\title{
THE MODEL OF THE PRODUCTION PROCESS FOR THE QUALITY MANAGEMENT
}

\author{
Zbigniew ALOT \\ Kazimierz Pulaski University of Technology and Humanities in Radom \\ Faculty of Mechanical Engineering, Radom, Poland \\ e-mail: zbigniew.alot@uthrad.pl
}

\begin{abstract}
This article is a result of the research on the models of the production processes for the quality management and their identification. It discusses the classical model and the indicators for evaluating the capabilities by taking as its starting point the assumption of the normal distribution of the process characteristics. The division of the process types proposed by ISO 21747:2006 standard introducing models for non-stationary processes is presented. A general process model that allows in any real case to precisely describe the statistical characteristics of the process is proposed. It gives the opportunity for more detailed description, in comparison to the model proposed by ISO 21747:2006 standard, of the process characteristics and determining its capability. This model contains the type of process, statistical distribution, and the method for determining the capability and performance (long-term capability) of the process. One of the model elements is proposed, own classification and resulting set of process types. The classification follows the recommendations of ISO 21747:2006 introducing models for the non-stationary processes. However, the set of the process types allows, beyond a more precise description of the process characteristics, its usage to monitor the process.
\end{abstract}

Keywords: model of the process, identification, process evaluation, statistical process control, quality management.

\section{Introduction}

One of the principles adopted in managing the modern organization is the use of a process approach. In this approach, one sees the activities carried out in the organization as a system of interrelated processes. The concept of the process is defined in the standards of quality management as "a set of activities interrelated or interacting, which transform inputs into outputs" (PN-EN ISO 9000, 2006). There are many definitions and process models presented in the literature. The best known are Oakland's (Oakland, 2003, p.14), Taguchi's (Taguchi, et al., 1989, p.23), and the so-called basic model (Yang, ElHaik, 2003, p.28).

Obtaining certain level of the quality of the products or services requires creating a stable and repeatable production processes and possessing appropriate to the needs abilities to realize the characteristics of product quality within a set range. The ability to achieve the objectives also concerns the management processes. Achieving such a state of the processes is one of the basic tasks of the management including quality management.
The subject of the evaluation and the control is the characteristics of the products and services that are the result of processes or characteristics of the processes. Many characteristics are measurable characteristics for which the best-known values were determined, called as $\mathrm{T}$ nominal values. The range limits for the numerical characteristic can be bounded on one side or both sides. Thus, the boundaries may be of two types:

- double-side limits, consisting of both lower specification limit (LSL) and upper specification limit (USL),

- one-side limits, that is, consisting either LSL or USL.

If the value of $\mathrm{T}$ is not defined, it is most commonly accepted that for the calculations, it is a half of the tolerance range $(\mathrm{USL} \div \mathrm{LSL})$ :

$$
\mathrm{T}=\frac{\mathrm{USL}+\mathrm{LSL}}{2}
$$


In the modern management and quality control concepts is more widely used philosophy proposed by Taguchi. It assumes that for each characteristic of the product (and for a process parameter), it is possible to determine the status $\mathrm{x}_{0}$ in which the product meets the best the needs of the user.

This condition can be described as a target or an optimal. Deviation of the actual values of the characteristic from this state is associated with a social loss. Taguchi assumed that the product not having the optimal characteristic has a lower value in use and is less resistant to interference than optimal product. Because of the incomplete use value, the losses are borne by the user and society.

There is a unique function for each attribute determining the relationship between the deviation of the characteristic from optimal value and the value of loss suffered. The function proposed by Taguchi is quadratic loss function of the form (Taguchi, et al., 1989, p.14; Tkaczyk, Kowalska-Napora, 2012, p.246)

$$
\mathrm{L}(\mathrm{x})=\mathrm{k}\left(\mathrm{x}-\mathrm{x}_{0}\right)^{2}
$$

where:

$\mathrm{k}$ - is the constant calculated on the basis of the loss that is borne in borderline case:

$$
\mathrm{k}=\frac{\mathrm{A}}{\mathrm{x}_{\mathrm{g}}{ }^{2}}
$$

A - is the cost of the product, processing, utilization, and so on,

$\mathrm{X}_{\mathrm{g}}$ - is the limit value.

Meanwhile, the variation is a natural phenomenon that occurs constantly in practice. It is the reason of overtaking regulatory actions, especially when variability of the outputs exceeds some acceptable in the given conditions range. This requires, among other things, evaluation and process control as the components of a management function.

As the variability of processes and product characteristics can be described mainly in terms of statistics, the statistical methods and the area of expertise referred to as "statistical process control" are important in its reduction. Most of these methods also require computer support for the effective application.
To monitor the status of the process, the Shewhart control charts are traditionally used. The control limits are determined based on the assumption that the process is stabilized, which means that the stability in time of the expected value and the standard deviation of the variable is the subject to the normal distribution. Under these assumptions, the statistical parameters and the process control limits of the charts are determined from the parameters of the samples taken from the process in the phase of preliminary tests.

If the process satisfies the assumptions of the stability - we say often that it is "under control" - the characteristic of the quality in time is represented by a model often referred as "Shewhart process model" in the form:

$$
\mathrm{x}_{\mathrm{t}}=\mu+\varepsilon_{\mathrm{t}} \quad \mathrm{t}=1,2, \ldots .
$$

where:

$\mathrm{x}_{\mathrm{t}}-$ is the value of the variable (product characteristics) at time $t$,

$\mu-$ is the process constant,

$\varepsilon_{t}-$ is the variable of the normal distribution $\mathrm{N}$ $(0, \sigma)$ representing the random influences.

The natural dispersion of the measurement results of the process quality characteristics resulting from technological conditions is referred to the term "natural variability of the process" (PN-ISO 35342:2010). This is the range defined by the two limits, usually denoted in the literature as:

UCL - upper control limit,

LCL - lower control limit.

The basis for the process control is an ascertainment, arising from the principles of probability and mathematical statistics, that in the regulated process, controlled property of the next products should fit around its expected value in natural limits.

Limitations such as UCL and LCL are defined as a multiple of the standard deviation of the normal distribution of probability of the process random variables from the expected value. 


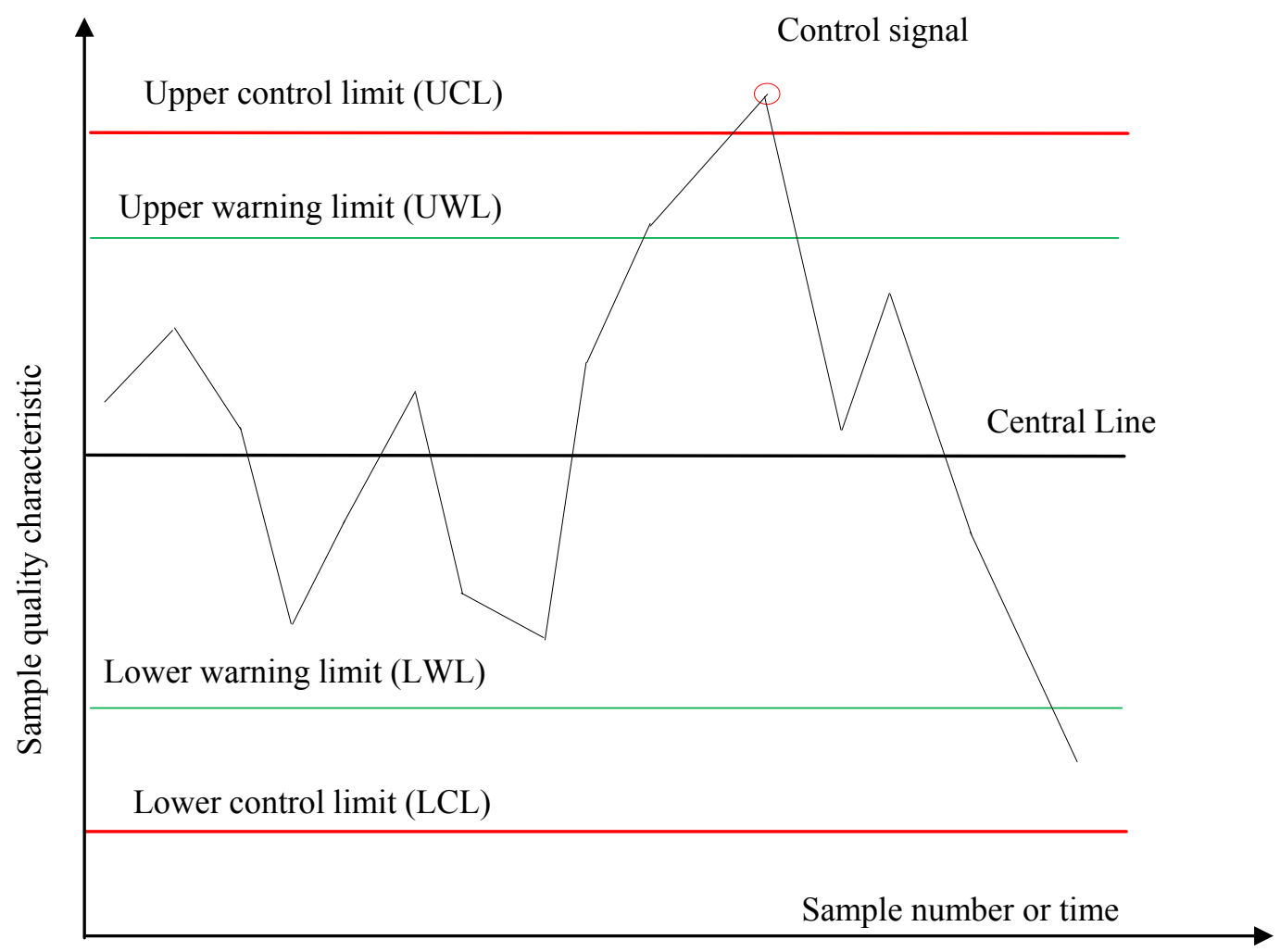

Figure 1. Schema of the main track of the control card (source: own study based on Montgomery (2009); DaimlerChrysler Corporation, et al. (2005); Dietrych and Schulze (2010); Oakland (2003))

Depending on the adopted multiple, the probability of exceeding these control limits is different and decreases with increasing the size of the limitations:

$$
\begin{aligned}
\mathrm{UCL} & =\mu+\mathrm{k} \times \sigma \\
\mathrm{LCL} & =\mu-\mathrm{k} \times \sigma
\end{aligned}
$$

where:

$\mu-$ is the expected value of the characteristic in the process,

$\sigma-$ is the standard deviation of the characteristic in the process,

$\mathrm{k}-$ is a constant.

In practical applications, the value of $\mathrm{k}$ is usually taken as 3 . The values $k=1$ and 2 are used as special limits, the so-called alert limits (internal control limits), regardless of the UCL and LCL, which are defined as external. In most control charts, control limits as well as the points on the card concern not only individual measurements but also the mean values of the $n$-element samples ( $n=2$ to 10$)$. Therefore, the standard deviation for determining the line on the charts concerns dispersion of the mean of the samples ${ }^{1}$.

With these assumptions, the probability of the occurrence of characteristics values within the control limits is $99.73 \%$. Exceeding by the controlled characteristic, the line UCL or LCL, whose values are determined statistically on the basis of measurements from the sample, means deregulation of the process stability. This is illustrated in Fig. 1.

Basic issues related to the process control are to determine whether the process is statistically regulated and whether the actual value of the product characteristics is consistent with the normative characteristics.

These findings are realized through the use of control cards and the calculations of the process capability and performance indicators. In case of noncompliance is undertaken detailed, substantive analysis and specific corrective action.

\footnotetext{
${ }^{1}$ Different ways of calculating the standard deviation are presented in Chapter 2.
} 
In accordance with the modern concepts of the quality management in the area of the production, it comes down to solve the following problems:

- effective monitoring of the variability of the production processes and their ability to manufacture products with a given level of quality,

- response to changes in the process, in particular the locations of the position and the reasons of the formation of various types of inconsistency with the specifications of the products,

- improving processes by reducing the variability of their parameters and hence the variability of the quality of products.

Actions in process improvement using the control card by Montgomery (2009, p.186) are shown in Fig. 2.

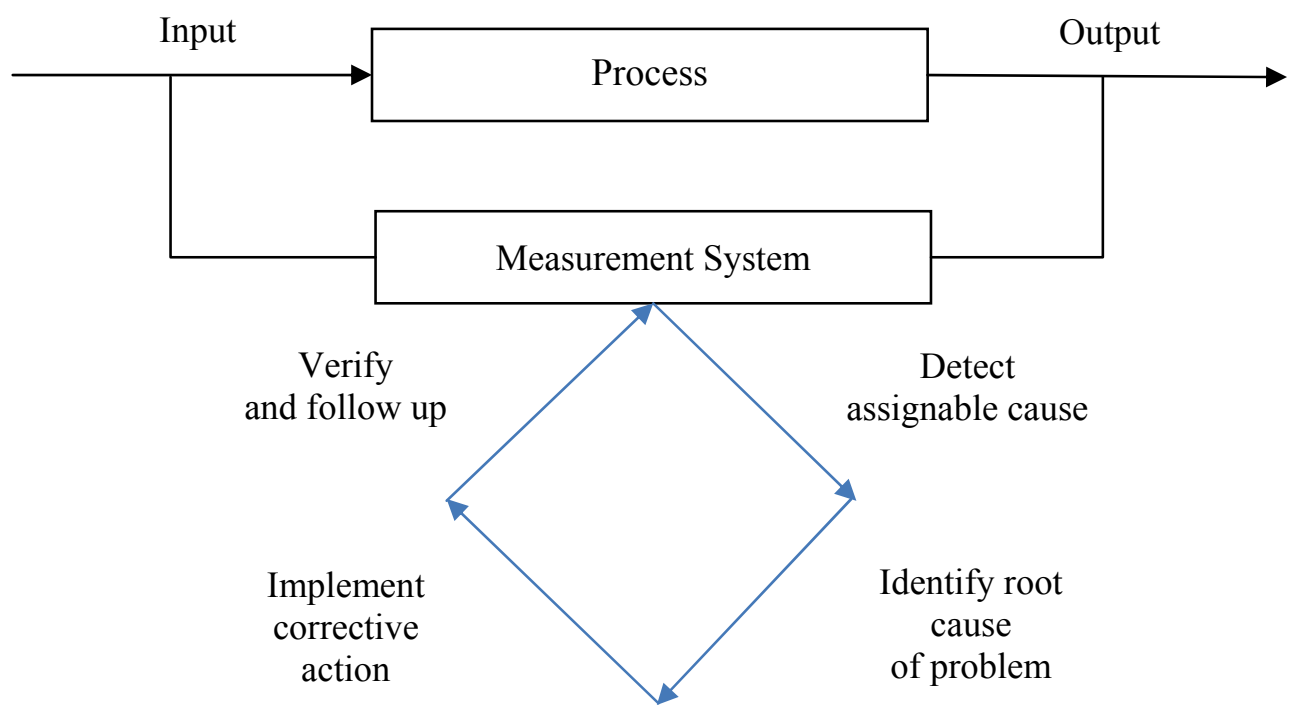

Figure 2. Process improvement using the control chart (source: Montgomery, 2009, p.186)

\section{Evaluation of the process capability and performance in the classical model}

In addition to the stability of the process, the important issue is the compliance of controlled characteristic with the technical requirements. The reasons for its absence can be:

- displacement of the expected value of the characteristic (parameter) in regard to the nominal value specified in the documentation,

- inconsistency in the value of the standard deviation, causing the possibility of exceeding by some copies of the product specified tolerance for the characteristic,

- the occurrence of the two events mentioned above at the same time.
The difference between UCL and LCL determines the so-called proper process variability (PN-ISO $3534-2,2010$, p.31) (a natural range of the process), which should not be less than the requirements specified by the permissible tolerance for a given characteristic.

The real process capability, resulting from its natural characteristics (position and dispersion) related to the requirements (technical), is defined by various indicators. They are mostly categorized as indicators of the capability (possibility) and indicators of performance (efficiency) (PN-ISO 3534-2, 2010, p.51, 55). Both groups are similar in mathematical formulas. The difference between them results from the adopted method of determining the natural variability of the process. 
General formula for the indicators is

$$
\begin{aligned}
\mathrm{w} & =\frac{\text { Range of the specification }}{\text { Range of the natural variability }} \\
& =\frac{\text { USL-LSL }}{\text { UCL-LCL }}
\end{aligned}
$$

where: USL and LSL are the upper and lower specification limits, respectively.

Often random sample of size $M$ is the result of gathering the data in the form of small, n-element samples characterizing the process in a short period of time. Many small samples in $\mathrm{N}$ number, accumulated over a long period, characterize process comprehensively, revealing the various factors affecting its variability.

When the data set consists of a number of samples, such as data collected for the control cards, variability of the value of the certain characteristic (the dispersion of random variable) can be described in two ways that are only seemingly similar. In fact, one can calculate two different variability indicators. The first one is the usual standard deviation of all observations (one omits the fact that the data consist of many samples):

$$
\sigma_{X}=S_{X}=\sqrt{\frac{1}{M-1} \sum_{i=1}^{i=M}\left(X_{i}-\bar{X}\right)^{2}}
$$

where

$$
\overline{\mathrm{X}}-\text { is the mean in the random sample, }
$$

$\mathrm{M}$ - is the number of observation in the random sample.

The second one is an estimator of the process variability based on the internal variability of the samples. The internal variability of the sample in turn can be described on the grounds of the ranges, standard deviations, or variations. The variability of the characteristic in the population determined on the basis of the mean value of the sample ranges is

$$
\sigma_{\mathrm{X}}^{\mathrm{R}} \approx \hat{\sigma}_{\mathrm{X}}^{\mathrm{R}}=\frac{\overline{\mathrm{R}}}{\mathrm{d}_{2}}=\mathrm{b}_{\mathrm{n}} \overline{\mathrm{R}}
$$

where

$$
\begin{aligned}
& \bar{R}=\frac{1}{N} \sum_{i=1}^{i=N} R_{i} \\
& R_{i}=\max _{j}\left\{X_{j}\right\}-\min _{j}\left\{X_{j}\right\} \text { for } j=1,2, \ldots
\end{aligned}
$$

$b_{n}, d_{2}$ are fixed values depending on the size of the n-sample.

The estimate of the standard deviation for the value of the variable in the population, based on the standard deviation of the samples, is the mean value of the modified standard values of the sample deviations:

$$
\begin{aligned}
& \sigma_{X}^{S} \approx \hat{\sigma}_{X}^{S}=a(n) \bar{S}=a(n) \frac{1}{N} \sum_{i=1}^{i=N} S_{i} \\
& S_{i}=\sqrt{\frac{1}{n-1} \sum_{j=1}^{j=n}\left(X_{j}-\bar{X}_{i}\right)^{2}}
\end{aligned}
$$

where:

$\mathrm{S}_{\mathrm{i}}-$ is the standard deviation from i sample,

$a(n)$ - is the fixed value that depends on the size of the sample.

The estimate of the standard deviation for the value of the variable in the population can also be made based on the variance of the samples:

$$
\sigma_{\mathrm{X}}^{\mathrm{S}^{2}} \approx \hat{\sigma}_{\mathrm{X}}^{\mathrm{S}^{2}}=\overline{\mathrm{S}}^{2}=\sqrt{\frac{\sum_{\mathrm{i}=1}^{\mathrm{i}=\mathrm{N}} \mathrm{S}_{\mathrm{i}}^{2}}{\mathrm{~N}}}
$$

where:

$\mathrm{N}$ - is the number of samples comprising random sample.

It should be noted that estimating the process variation on the basis of the variation within the samples is acceptable if a process is statistically stable. A detailed discussion on the difference between the general and the internal variance of the process is presented in the literature (DaimlerChrysler Corporation, et al., 2005; Montgomery, 2009). If the process is not stable, very significant differences between the standard deviation determined on the total sample of size $\mathrm{M}$ and the standard deviation determined on the n-element samples may occur depending on the degree of instability of the process.

Kotz and Johnson (1993, p.39-41) specified in their book, also quoting other authors, that the variability used in capability indicators (denoted by $\mathrm{C}_{\mathrm{p}}$ ) is determined as a rule based on the intersample variability, while the performance indicators $\left(\mathrm{P}_{\mathrm{p}}\right)$ are based on variability of the entire sample. 
Similarly, although generally, the concepts of performance and capability were specified in PN-ISO 3534-2:2010 and ISO 21747:2006. The capability of the process is the statistical estimator for the measurement result of a process characteristic for which it was demonstrated that it is in a state of a statistical control, describing the ability of meeting by the process the requirements set on a particular characteristic.

The process performance is a statistical result measure of the measurement of the process characteristics that cannot be in a state of a statistical control.

In the new standards (PN-ISO 3534-2:2010, p.55), in the contrast to the previous one (PN-ISO $8258+\mathrm{ACl} 11996$, pp.15-16), the problem with calculating the indicators on the basis of internal variability is noted, concluding that "in the case of the normal distribution, under certain circumstances, the standard deviation $\mathrm{s}_{\mathrm{w}}$ can replace total standard deviation $\mathrm{s}_{\mathrm{t}}$."

The essence of the difference between the indicators is better reflected by the qualifications used especially in the automotive industry - short- and long-term capability indicators (DaimlerChrysler Corporation, et al., 2005, p.14). The short-term considerations related to the capabilities are based on the measurements collected from a single route of the operation. If these data do not reveal the special causes and the process is in a state of statistical control, one can calculate the short-term indicator (process capability). This type of the research is used to verify the initial items of the product produced by the process for an approval by the customer. Another application, sometimes called testing the capability of the machine, is to verify whether a new or redesigned process proceeds within the technical parameters.

In both group of the indicators, there are a few types. The types in both groups most often possess similar formulas. $\mathrm{C}_{\mathrm{p}}, \mathrm{C}_{\mathrm{r}}, \mathrm{C}_{\mathrm{pk}}, \mathrm{C}_{\mathrm{pl}}, \mathrm{C}_{\mathrm{pu}}$, and $\mathrm{K}$ are the capability indicators and $\mathrm{P}_{\mathrm{p}}, \mathrm{P}_{\mathrm{r}}, \mathrm{P}_{\mathrm{pk}}, \mathrm{P}_{\mathrm{pl}}$, and $\mathrm{P}_{\mathrm{pu}}$ are the performance indicators.

The following are the most commonly used types. Others are presented in the literature (Kotz and Johnson, 1993; Montgomery, 2009; Montgomery, Runger, 2003).
- Process capability indicator (potential capability) $-\mathrm{C}_{\mathrm{p}}$

$$
\mathrm{C}_{\mathrm{p}}=\frac{\mathrm{USL}-\mathrm{LSL}}{6 \sigma_{\mathrm{x}}^{\mathrm{R}, \mathrm{S}, \mathrm{S}^{2}}}
$$

where

$\sigma_{\mathrm{x}}^{\mathrm{R}, \mathrm{S}, \mathrm{S}^{2}}-$ is one of the estimators of the population standard deviation.

This is the simplest and most straightforward process capability indicator. Assuming a normal distribution of measurement results and the limits \pm 3 sigma, the quotient tells what part of the range of the normal curve is within the given range of the specification (where the mean is consistent with the nominal value, i.e., the process is centered).

If the population standard deviation is determined based on the entire sample, then the process performance indicator is determined (potential value):

$$
P_{p}=\frac{U S L-L S L}{6 \sigma_{x}}
$$

This rule also concerns the other types of the indicators.

- Upper/lower process capability indicator (upper/lower potential capability) $-\mathrm{C}_{\mathrm{pu}}, \mathrm{C}_{\mathrm{pl}}$

The main disadvantage of the $C_{p}$ indicators is the possibility of misinformation, if the center of the process does not coincide with the center of the tolerance range, that is, if it is not centered. Therefore, additional indicators are used.

$$
\begin{aligned}
& \mathrm{C}_{\mathrm{pl}}=\frac{\mu-\mathrm{LSL}}{3 \sigma} \\
& \mathrm{C}_{\mathrm{pu}}=\frac{\mathrm{USL}-\mu}{3 \sigma}
\end{aligned}
$$

- Minimal process capability indicator $-C_{p k}$

The total potential capability corrected by the shift of the expected value against the center of the tolerance range (sometimes referred as efficiency of the process) is

$$
\mathrm{C}_{\mathrm{pk}}=\min \left\{\mathrm{C}_{\mathrm{p} 1} ; \mathrm{C}_{\mathrm{pu}}\right\}=\min \left\{\frac{\mu-\mathrm{LSL}}{3 \sigma} ; \frac{\mathrm{USL}-\mu}{3 \sigma}\right\}
$$

If the expected value coincides with the center of the tolerance range, then

$$
\mathrm{C}_{\mathrm{pk}}=\mathrm{C}_{\mathrm{p}}
$$


The assumptions in the classical statistical process control (SPC) correspond to the model (1), which is not always adequate to the actual situation, what must be a fundamental characteristic of each model.

Also, the currently recommended methodological approach in ISO 7870-2 (ISO 7870-2:2013) to the quality control is a typical approach of a classical data analysis, assuming a priori model of the normal distribution and focusing on the estimation of its parameters. The need is pointed out only to examine the compliance of data with the process distribution and stability. If there is non-compliance with the distribution or stability, the procedure ends with a recommendation: "remove the determinable causes."

Practical situations in the industry led to a change in methodological approach, recognizing several classes of the process models, among which "Shewhart's processes" (normal) represent only one class. Recognition of the need for introducing the new models of processes took in some countries the official form of standardization guidelines and recommendations. Germany is an example, where in 2002 the DIN 55319 standard - Qualitätsfähigkeitskenngrößen - was developed.

Also several recommendations from companies (e.g., Ford) set as a basis for the control the need for analysis and process identification (DaimlerChrysler Corporation, et al., 2005, pp.81, 86) and the use of special methods, if the distribution is not compliant with the normal.

The new approach was formally introduced in 2007 by ISO 21747 (ISO 21747:2006). In this approach, by recognizing non-stationary processes, eight types of the processes were distinguished, called the models of the distribution, which are shown in Table 1. The term "model of the distribution" was interpreted as "a specific distribution or a class of the distributions" (ISO 21747:2006, p.1; PN-ISO 3534-2:2010, p.47).

Table 1. Basic features of the time-dependent distribution models

(source: ISO 21747:2006, p.14; Dietrych and Schulze, 2010, pp.312-322)

\begin{tabular}{|l|c|c|c|c|c|c|c|c|}
\hline \multirow{2}{*}{ Characteristic } & \multicolumn{7}{|c|}{ Time-dependent distribution models } \\
\cline { 2 - 11 } & A1 & A2 & B & C1 & C2 & C3 & C4 & D \\
\hline Location & $\mathrm{c}$ & $\mathrm{c}$ & $\mathrm{c}$ & $\mathrm{r}$ & $\mathrm{r}$ & $\mathrm{s}$ & $\mathrm{sr}$ & $\mathrm{sr}$ \\
\hline Dispersion & $\mathrm{c}$ & $\mathrm{c}$ & $\mathrm{sr}$ & $\mathrm{c}$ & $\mathrm{c}$ & $\mathrm{c}$ & $\mathrm{c}$ & sr \\
\hline $\begin{array}{l}\text { Instantaneous } \\
\text { distribution }\end{array}$ & $\mathrm{nd}$ & $1 \mathrm{~m}$ & $\mathrm{nd}$ & $\mathrm{nd}$ & $\mathrm{nd}$ & $\mathrm{as}$ & as & as \\
\hline $\begin{array}{l}\text { Outcoming } \\
\text { distribution }\end{array}$ & $\mathrm{nd}$ & $1 \mathrm{~m}$ & $1 \mathrm{~m}$ & $\mathrm{nd}$ & $1 \mathrm{~m}$ & as & as & as \\
\hline
\end{tabular}

The distribution of the characteristics in the standard means "the information on the probabilistic behavior of the characteristics" and "the class of the distribution" the particular family of the distributions in which each member has the same, common characteristics on which this family is fully described."

Classification was done on the basis of the criteria shown in the table. They include the characteristics of the location and dispersion of the distribution and also the characteristics of the momentary distributions and the resulting distribution.

The characteristics of the location and dispersion concern the nature of the variability of these parameters of the distribution. 


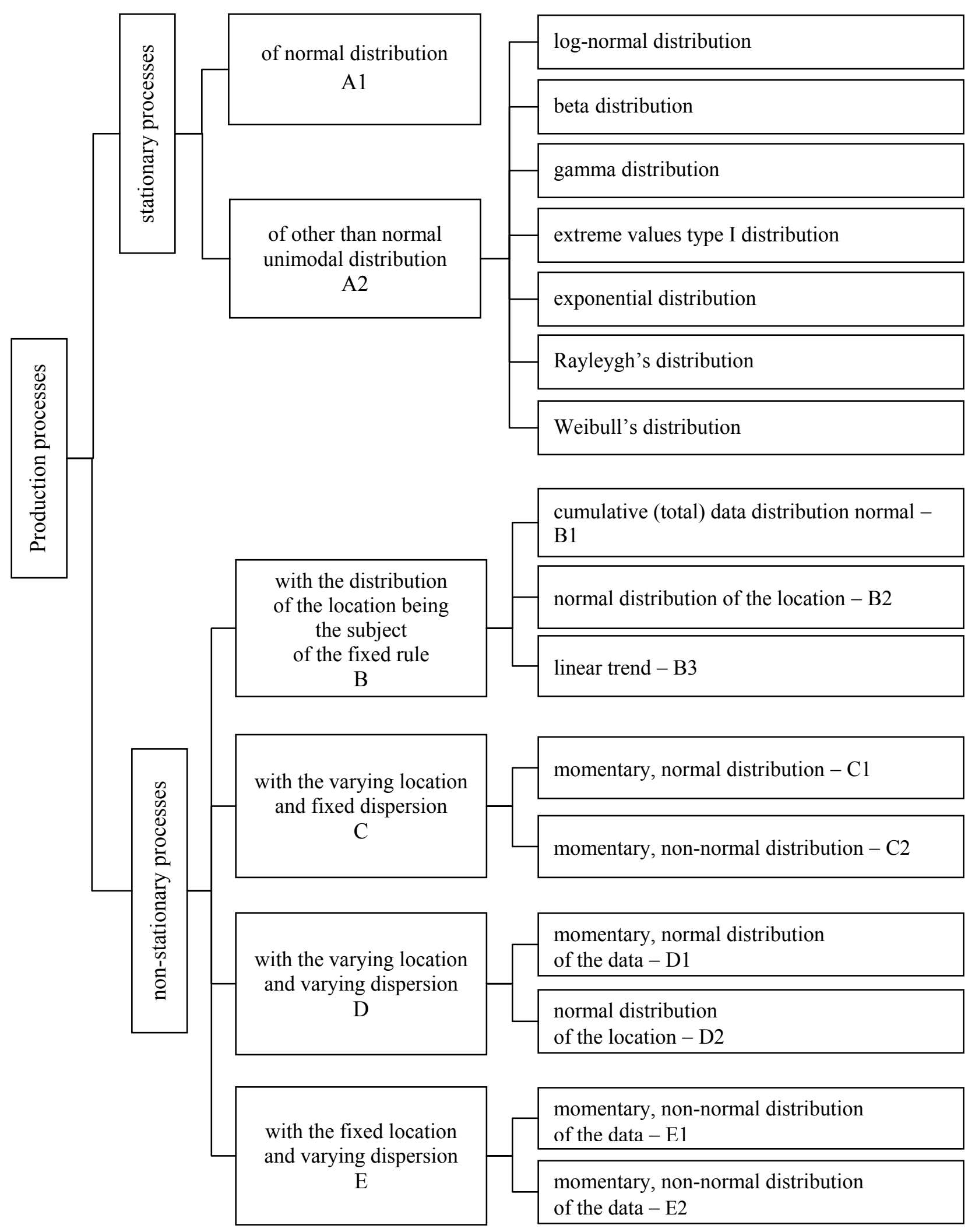

Figure 3. Classification of the production processes from the point of view of the statistical models of the distribution of the characteristics

(source: own study) 
The designations shall specify:

$\mathrm{c}$ - this parameter remains constant during the study period (longer period),

$\mathrm{r}$ - this parameter varies randomly,

$\mathrm{s}-$ this parameter changes in a systematic way,

$\mathrm{sr}$ - this parameter changes in a systematic and random way.

The characteristic of the distribution is marked, in turn, by the following abbreviations:

nd - normal distribution (normally distributed),

$1 \mathrm{~m}$ - other than the normal distribution, unimodal (one mode only),

as - distribution of any shape (other than normal).

The characteristics of the distributions (momentary, resulting) determine the type of the theoretical distribution describing very well the real process (empirical distribution).

Momentary distribution is characterized by keeping the characteristic when tested in the short term. These properties are based on measurements of the small samples, making up random sample. Usually, it is the time interval during which the sample is taken from the process.

The resulting distribution, sometimes called the output distribution of the process, is obtained from observing the process over a longer period of time. Then changes in the position of momentary distribution, in the dispersion of the measurement results, and even in the other parameters of the distribution are revealed.

Models of the time-dependent distributions are divided into four main categories:

A - processes with fixed location and dispersion in which the momentary distributions do not change and are in accordance with the output distribution,

B - processes with fixed location but a variable dispersion,
$\mathrm{C}$ - processes with constant dispersion but changing location in time,

D - processes with both variable characteristics.

The models of the A and $\mathrm{C}$ classes have the subclasses distinguished because of its practical meaning (ISO 21747:2006, p.14). They differ in shape of the resulting distribution and in cases of deviation from the stable state.

Despite the importance of formal recognition by the ISO-21747 of non-stationary processes in the SPC, their own classification was proposed.

It is one of the results of the study undertaken on the models of the production processes for the quality management purposes and their identification. An additional criterion was used in the proposed classification, besides the criteria adopted in the standard - "The distribution of the instantaneous position." An explicit division of location and the momentary dispersion of distribution was also adopted.

On the basis of the analysis of the various practical examples and the examples presented in the literature, the synthetic classification of the processes was made, which shown in Fig. 3.

For A2-type processes, the examples of the types of distributions were given. They do not exhaust all possibilities that may appear in the actual processes. Closer characteristics of the different types of processes were presented in Table 2.

On the basis of the five criteria shown in the columns of Table 2, 13 types of the processes into which each real process can be classified were distinguished. The last column gives the models that are also possible for use in determining the "natural capability of process."

The model includes a method for determining the ability of M1 and M2 and a statistical distribution or a group of distributions. 
Table 2. The characteristics of the types of the processes with the potential models of the statistical distributions

(source: own study)

\begin{tabular}{|c|c|c|c|c|c|c|}
\hline $\begin{array}{l}\text { Process } \\
\text { type }\end{array}$ & $\begin{array}{l}\text { Temporary } \\
\text { location }\end{array}$ & $\begin{array}{l}\text { Temporary } \\
\text { dispersion } \\
\text { (variance) }\end{array}$ & $\begin{array}{c}\text { Distribution } \\
\text { of temporary } \\
\text { position } \\
\text { (means) }\end{array}$ & \begin{tabular}{|c|} 
Distribution of \\
temporary data \\
(samples)
\end{tabular} & $\begin{array}{c}\text { Distribution of } \\
\text { total data } \\
\text { (populations) }\end{array}$ & $\begin{array}{c}\text { Model of determining range } \\
\text { dispersion }\end{array}$ \\
\hline A1 & Constant & Constant & - & Normal & Normal & $\begin{array}{c}\text { M1 } \\
\text { (Normal) }\end{array}$ \\
\hline A2 & Constant & Constant & - & IJMD & IJMD & M1-IJMD \\
\hline B1 & Variable & Constant & IJMD & Normal & Normal & $\begin{array}{l}\text { M2-a2-1 } \\
\text { M1-NR1 }\end{array}$ \\
\hline B2 & Variable & Constant & Normal & Normal & NN & $\begin{array}{c}\text { M1-MRN, } \\
\text { M1-NR2 } \equiv \text { M2-a2-2 }\end{array}$ \\
\hline B3 & Variable & Constant & Linear trend & Normal & $\mathrm{NN}$ & $\begin{array}{c}\text { M1- MRN } \\
\text { M2-a1 } \\
\end{array}$ \\
\hline B4 & Variable & Constant & Normal & Normal & Normal & $\begin{array}{l}\text { M2-a2-1 } \\
\text { M1-NR1 }\end{array}$ \\
\hline $\mathrm{C} 1$ & Variable & Constant & IJMD & Normal & $\mathrm{NN}$ & M1-MRN \\
\hline $\mathrm{C} 2$ & Variable & Constant & IJMD & IJMD & NN & M1-MRN \\
\hline D1 & Variable & Variable & IJMD & Normal & $\mathrm{NN}$ & M1-MRN \\
\hline D2 & Variable & Variable & Normal & IJMD & NN & M1-MRN \\
\hline D3 & Variable & Variable & NN & $\mathrm{NN}$ & $\mathrm{NN}$ & M1-MRN \\
\hline E1 & Constant & Variable & - & Normal & $\mathrm{NN}$ & $\begin{array}{c}\text { M1- MRN } \\
\text { M1-NR3 } \equiv \text { M2-a3 }\end{array}$ \\
\hline E2 & Constant & Variable & - & IJMD & $\mathrm{NN}$ & M1-MRN \\
\hline
\end{tabular}

where:

M1-IJMD - is the method of percentages (MOP), matched unimodal distribution other than the normal,

M1-MRN - is the MUP, matched mixture of normal distributions,

M1-NR1 - is the MUP, the normal distribution with the total variance by analysis of variance (ANOVA) (normal expanded),

M1-NR2 - is the MUP, a normal distribution with variance by a combination of the total variance and the variance of the instantaneous position,

M1-NR3 - is the MUP, a normal distribution with variance total by a mixture of normal distributions,

M2-a1 - is the method of explicit inclusion of an additional variation of "a1",

M2-a2-1 - is the method of explicit inclusion of an additional variation of "a2-1",
M2-a2-2 - is the method of explicit inclusion of an additional variation of "a2-2",

M2-a3 - is the method explicit inclusion of diverse temporary variance.

Designations in Table 2 specify the following models or the group of the distributions:

IJMD - other than the normal unimodal distribution,

NR - a normal distribution "extended",

$\mathrm{NN}-$ a distribution is not normal and not unimodal,

MRN - a mixture of the normal distributions.

Here, expanded distribution means fitted statistical distribution in which "the natural variability of the process" has been calculated, using the additional process variability, by M2 method described in Chapter 4. 


\section{The model of the production process in the terms of nonclassical assumptions}

The concept of the model is defined differently in the literature, depending on the field of knowledge and needs in solving specific problems.

According to Tyranska, model is a "simplified representation or representation of reality (from the Latin modus means to measure, model, the way in which you do things). It presents the structure, features, operation of existing or proposed facility, providing information that will enable knowledge about it" (Leksykon Zarządzania, 2007, p.343).

Model focuses on the elements characterizing the object from a particular point of view or that have significant impact on the specific process.

The object of interest in this work is a model that aims to precisely determine the capability and performance of the process with more general than classical assumptions. The model of the process, including the method of identification, is shown in Fig. 4.

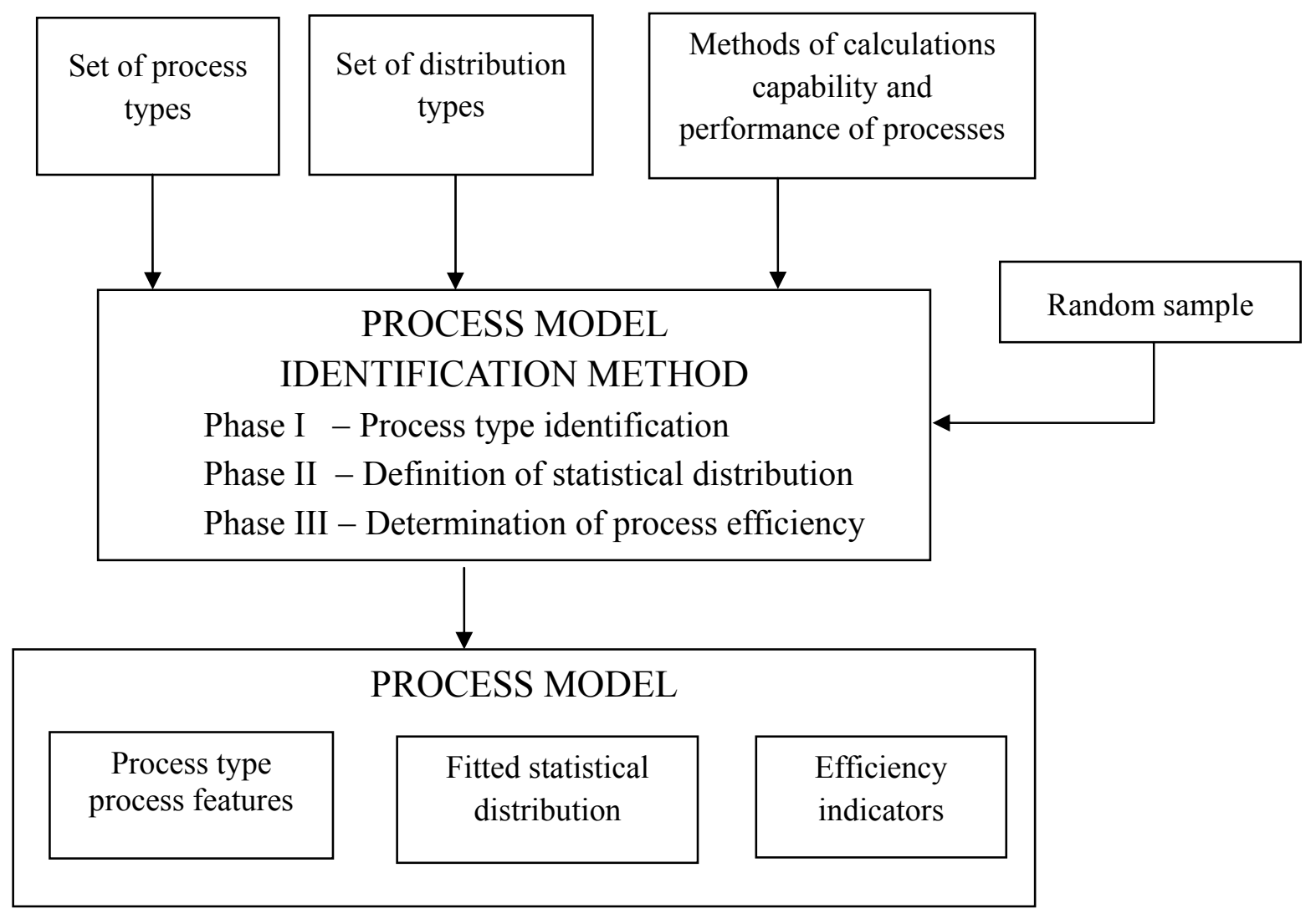

Figure 4. Graphical representation of the model of the production process in terms of nonclassical assumptions

(source: own study)

The model presented on it is a graphical, schematic description of the production process in the terms of the nonclassical assumptions for its evaluation and control. Similar to the mathematical models, it consists of two basic parts:

- describing in a certain way, a set of variables and relationships between them (in the mathematical models in the form of an equation or set of equations),

- presenting the method of determining the parameters (equation or set of equations) called estimation parameters of the model. 
Both parts can be specified by the model in the broad sense. The first part is a model in the strict sense. This first part is mostly a mathematical model in the usual sense but without the second part "model" is only a vague description of reality without practical application.

This division is clearly visible in Fig. 2. A section called process model is a model in the strict sense. With the "method of identifying a process model," it is a model in the broad sense. The model consists of:

- the type of the process and its characteristics,

- statistical distribution characterizing the process,

- evaluation of the process performance.

The identification method based on a random sample identifies parameters of the model (which well describes the process) for the specific process. From the set of types of the processes, the type of process and its characteristics are selected. It is the phase of the process type identification.

\section{The performance evaluation of the non-stationary processes}

If the distribution of the characteristics is not a normal distribution or the process is non-stationary, the calculations of the capability indicators vary in relation to the part concerning the natural variability of the process UCL and LCL.

By analogy to the normal distribution, it is also assumed in other distributions that the part of the population covered by the division of the natural variability and the parts that are located above UCL line and below LCL line should be the same as in normal distribution. Owing to the symmetry of the normal distribution, part of the population outside the UCL and LCL lines are identical.

From the analysis of the normal distribution, we know that UCL and LCL lines determine the area covering $99.73 \%$ of the population (fields below the curve of the normal distribution). Part beyond this area is $0.27 \%$, respectively, $0.135 \%$ above UCL and $0.135 \%$ below LCL. These lines are quantile in normal distribution of size $p=0.99865$ for UCL line and $p=0.00135$ for LCL line. Expected value in the normal distribution is a quantile of the size $p=0.5$, that is, median.
These three general characteristic for the distribution values are, therefore, important also for other distributions than normal. Given quantile orders of the magnitude apply only if you take the natural variability of the process according to the rule $\mathrm{k}=3$ in the formula $\mu \pm \mathrm{k} * \sigma$. If you accept a different value for $\mathrm{k}$, appropriate quantile orders of the magnitude should be determined based on the cumulative distribution function of the standardized normal distribution.

Assuming, for any distribution, the following determinations:

$M_{e}$ - is the median of the distribution (the quantile of the size $\mathrm{p}=0.5$ ),

$\mathrm{Q}_{\mathrm{L}}$ - is the quantile of the size $\mathrm{p}=0.00135$ (or adequate for the LCL line in accordance with the formula $\mu \pm \mathrm{k} * \sigma$ ),

$\mathrm{Q}_{\mathrm{U}}$ - is the quantile of the size $\mathrm{p}=0.99865$ (or adequate for the UCL line in accordance with the formula $\mu \pm \mathrm{k} * \sigma)$,

the natural range of the process variability (the range of the reference according to PN-ISO 3534-2, 2010, p.49) is determined by the difference

$$
\Delta=\mathrm{Q}_{\mathrm{U}}-\mathrm{Q}_{\mathrm{L}}
$$

Accordingly, the upper and lower ranges of the reference are specified by dependencies:

$$
\begin{aligned}
\Delta_{\mathrm{U}} & =\mathrm{Q}_{\mathrm{U}}-\hat{\mu} \\
\Delta_{\mathrm{L}} & =\hat{\mu}-\mathrm{Q}_{\mathrm{L}}
\end{aligned}
$$

This method of determining the natural variability is called the method of percentages, M1 (Dietrych, Schulze, 2010, p.337). It is used for calculating the performance indicators for distributions other than normal. As you can see, it is more general.

When applied to the normal distribution, this method gives the same values of the indicators as formulas described for the normal distribution. The calculations are carried out on the entire random sample and do not result from the instantaneous characteristics of the process (n-element samples).

In case of distributions other than normal, often the preferred method of determining the location of the process is the adoption of (ISO/TR 22514-4:2007, p.13): 


$$
\hat{\mu}=\mathrm{M}_{\mathrm{e}}
$$

and then upper and lower ranges of the reference are described by dependencies (ISO/TR 22514-4:2007, pp.18, 27):

$$
\begin{aligned}
& \Delta_{\mathrm{U}}=\mathrm{Q}_{\mathrm{U}}-\mathrm{M}_{\mathrm{e}} \\
& \Delta_{\mathrm{L}}=\mathrm{M}_{\mathrm{e}}-\mathrm{Q}_{\mathrm{L}}
\end{aligned}
$$

For clarity the variable location or dispersion can be used method M2 of explicit inclusion of additional process variability $\mu_{\text {add }}$ not resulting from instantaneous variability (variability in samples):

$$
\Delta+\mu_{\text {add }}=(\mathrm{ULC}-\mathrm{LCL})+\mu_{\mathrm{add}}
$$

The range of the reference $\Delta$ is defined here based on the sample characteristics that is instantaneous variability (short term) of the process. These estimators neglect the variability among samples, and only in that case, it is recommended to use M2 method.

Additional variability according to the standard ISO21747 can be defined in two ways (ISO 21747:2006, p.27; Dietrych and Schulze, 2010, p.339):

$$
\hat{\mu}_{\text {add }}=\max _{i \in(1, N)}\left(\bar{x}_{i}\right)-\min _{i \in(1, N)}\left(\bar{x}_{i}\right)-\text { by the }
$$

spread of the sample mean,

$\mu_{\text {add }}=$ variance (ANOVA) - by the method of the analysis of the variance.

The standard doesn't provide either the detailed way of including additional variability determined by the ANOVA method or the models of the processes for which the appropriate variant (23) and (24) of the additional variability should be applied. The way (23) is marked in Table 2 as M2-a1 and (24) as M2a2-1.

The basic evaluation indicators, in case of nonstationary processes (being characterized by the variable location or dispersion), are the performance indicators.

The formulas of these indicators, including the additional variability and the definition of the ranges of the references, can be written as follows (ISO 21747:2006, p.26):

$$
\begin{aligned}
& \mathrm{P}_{\mathrm{p}}=\frac{\mathrm{USL}-\text { LSL }}{\Delta+\mu_{\text {add }}} \\
& \mathrm{P}_{\mathrm{pl}}=\frac{\mu-\text { LSL }}{\Delta_{\mathrm{L}}+1 / 2 \mu_{\text {add }}}
\end{aligned}
$$

$$
\mathrm{P}_{\mathrm{pu}}=\frac{\mathrm{USL}-\mu}{\Delta_{\mathrm{U}}+1 / 2 \mu_{\mathrm{add}}}
$$

The ranges of the references are defined in this case, as described earlier, based on the internal variability of the process:

$$
\begin{aligned}
& \Delta=\mathrm{Q}_{\mathrm{U}}-\mathrm{Q}_{\mathrm{L}}=6 \hat{\sigma} \\
& \Delta_{\mathrm{U}}=\mathrm{Q}_{\mathrm{U}}-\hat{\mu}=3 \hat{\sigma} \\
& \Delta_{\mathrm{L}}=\hat{\mu}-\mathrm{Q}_{\mathrm{L}}=3 \hat{\sigma}
\end{aligned}
$$

According to the guidelines in the standard, the use of the method M2 is possible if the samples come from a normal distribution; however, the resulting distribution can be different from the normal. Only then, on the basis of the variances of the samples, the natural variability caused by a momentary dispersion can be determined correctly. In case of normal distribution, the estimators of the variance $\hat{\sigma}$ in equations (8), (11), and (13) can be used.

As seen from dependencies (26) and (27), the standard assumes that an additional variation is distributed symmetrically to the instantaneous variation, which is not always true.

In some types of the processes (B2, E1), there is potential possibility for the application of the method M2 with additional variability defined in a special way. In Table 2, this is represented as a method M2a2-2 and M2-a3. In these cases, the total dispersion of the measurement results caused by systematic and random variability can be determined in the manner similar to that of the method of the variance components. The following dependencies are met:

$$
\begin{aligned}
& \Delta_{\mathrm{U}}+1 / 2 \mu_{\text {add }}=3 \sigma_{\mathrm{c}} \\
& \Delta_{\mathrm{L}}+1 / 2 \mu_{\mathrm{add}}=3 \sigma_{\mathrm{c}} \\
& \mathrm{UCL}_{\mathrm{R}}=\mu+3 \sigma_{\mathrm{c}} \\
& \mathrm{LCL}_{\mathrm{R}}=\mu-3 \sigma_{\mathrm{c}}
\end{aligned}
$$

where:

$\sigma_{\mathrm{c}}-$ is the overall standard deviation of the process, $\mathrm{UCL}_{\mathrm{R}}, \mathrm{LCL}_{\mathrm{R}}$ - are the limits of the variability in the process with the additional fluctuation of the location corresponding to the natural variability of the stable process and equivalent to the quantiles $\mathrm{Q}_{\mathrm{U}}$ and $\mathrm{Q}_{\mathrm{L}}$, respectively. 
This requires deeper research. However, it can be retained the intended meaning, that for the processes of this type, detailed dependences of the following form can be defined:

$$
\begin{aligned}
& \mathrm{UCL}_{\mathrm{R}}=\mathrm{f}\left(\mu\left(\sigma_{\varepsilon} \sigma_{\tau}, \mathrm{n}\right)\right. \\
& \mathrm{LCL}_{\mathrm{R}}=\mathrm{f}\left(\mu\left(\sigma_{\varepsilon} \sigma_{\tau}, \mathrm{n}\right)\right.
\end{aligned}
$$

where:

$\sigma_{\varepsilon}-$ is the standard instantaneous deviation of the process ( in samples),

$\sigma_{\tau}$ - is the standard deviation among groups (among samples).

On the basis of the logical analysis, the characteristic of the methods and particular types of the processes, as well as the results of the research for applying the methods in the specific cases, the choice was made of the potentially possible use of the methods for the calculations in the individual categories of processes. Such a list is shown in Table 3.

For each process, the methods in the order of their precision are given. Methods selected as the primary (model) are in bold.

The statement also includes another method of symbol M4, that is, "the inconsistency fraction." It can be applied especially when company is using the concept of "six sigma." The idea of this method is derived from the widely used definitions of $\mathrm{C}_{\mathrm{p}}, \mathrm{C}_{\mathrm{pk}}$ and $\mathrm{P}_{\mathrm{p}}, \mathrm{P}_{\mathrm{pk}}$ for the "ideal process" with a measured characteristic being a subject to the normal distribution.

For this process, the standard deviation in a long period is equal to the short-term deviation. With the extension of these measures to the characteristics that are not the subject to the normal distribution, it should be taken such a point of view that they are to be managerial tools that reflect the consistency of the current values of the characteristics with their limitations in the specification (ISO/TR 225144:2007, p.21).

That's why the measures have to be related to the fraction of the real consistent or inconsistent values. This is due to the fact that in the same fraction of the compatibility or incompatibility, the same capability and performance is obtained regardless of the shape of the distribution of the real values of the characteristic.

Usually, we distinguish the upper and lower fractions of the inconsistent units. The upper fraction of the inconsistent units $\mathrm{pU}$ is a fraction of the distribution of the characteristics for the values larger than the upper limit of the specification USL (PN-ISO 3534$2: 2010$, p.47). The lower fraction of the inconsistent units $\mathrm{pL}$ is a fraction of the distribution of the characteristics for the values smaller than the lower limit of the specification LSL (PN-ISO 3534-2:2010, p.47).

For the method of inconsistency fraction and the normal distribution, the estimators for the capability indicators equivalent to the indicators being traditionally defined (ISO/TR 22514-4:2007, pp.21, 22) can be described as

$$
\begin{aligned}
& \hat{\mathrm{C}}_{\mathrm{p}}=\frac{\hat{\mathrm{C}}_{\mathrm{pu}}+\hat{\mathrm{C}}_{\mathrm{pl}}}{2} \\
& \hat{\mathrm{C}}_{\mathrm{pk}}=\min \left\{\hat{\mathrm{C}}_{\mathrm{pu}} ; \hat{\mathrm{C}}_{\mathrm{pl}}\right\} \\
& \hat{\mathrm{C}}_{\mathrm{pu}}=\frac{\mathrm{z}_{1-\hat{\mathrm{p} U}}}{3} \\
& \hat{\mathrm{C}}_{\mathrm{pl}}=\frac{\mathrm{z}_{1-\hat{\mathrm{p} L}}}{3}
\end{aligned}
$$

where:

$\hat{\mathrm{p}} \mathrm{U}, \hat{\mathrm{p}} \mathrm{L}$ - are the estimators of the inconsistency fraction accordingly for the beyond upper and lower limit of the specification (upper and lower fractions of the inconsistent units),

$\mathrm{z}_{1-\hat{\mathrm{p} U} \mathrm{U}}, \mathrm{z}_{1-\hat{\mathrm{p}} \mathrm{L}}-$ are the quantiles of the size $\alpha$ of the standard normal distribution equivalent to the values accordingly for the upper and lower limit of the specification (from $-\infty$ to $\alpha$ ).

The above quantiles in case of the normal distribution can be determined from the general dependency:

$$
\begin{aligned}
& \mathrm{z}_{1-\hat{\mathrm{p} U}}=\frac{\mathrm{USL}-\mu}{\sigma} \\
& \mathrm{z}_{\hat{\mathrm{p}} \mathrm{L}}=\frac{\mathrm{LSL}-\mu}{\sigma}
\end{aligned}
$$


Table 3. Potential methods for determining the natural capability of the particular types of the processes (source: own study)

\begin{tabular}{|c|c|c|c|c|c|c|c|c|c|c|c|c|}
\hline \multirow{3}{*}{$\begin{array}{c}\text { Own } \\
\text { mod- } \\
\text { el }\end{array}$} & \multirow{3}{*}{ Method } & \multicolumn{2}{|c|}{ I } & \multicolumn{3}{|c|}{ d } & \multicolumn{3}{|c|}{$\mathbf{a}$} & \multirow{3}{*}{$\mathbf{F}(\mathbf{L})$} & \multirow{3}{*}{$\mathbf{F}(\mathbf{U})$} & \multirow{3}{*}{ Comments } \\
\hline & & 1 & 3 & 1 & 4 & 6 & 1 & $\begin{array}{c}2-1 \\
\text { ANOVA } \\
\end{array}$ & $\begin{array}{c}2-2 \\
\text { ANOVA } \\
\end{array}$ & & & \\
\hline & & $\bar{X}$ & $X_{50}$ & $\overline{S^{2}}$ & $\bar{S}$ & $\begin{array}{l}X_{0,135} \\
X_{99,9865}\end{array}$ & $R_{s}$ & $\sigma_{c}$ & $\sigma_{k}$ & & & \\
\hline \multirow{4}{*}{ A1 } & M1-1,4 & $\mathrm{x}$ & & & $\mathrm{x}$ & & & & & & & \\
\hline & M1-3,6 & & $\mathbf{x}$ & & & $\mathbf{x}$ & & & & & & $\begin{array}{l}\text { Normal } \\
\text { distribution }\end{array}$ \\
\hline & M1-1,1 & $\mathbf{x}$ & & $\mathrm{x}$ & & & & & & & & \\
\hline & M4 & & & & & & & & & $\mathrm{x}$ & $\mathrm{x}$ & \\
\hline \multirow[t]{2}{*}{ A2 } & M1-3,6 & & $\mathbf{x}$ & & & $\mathbf{x}$ & & & & & & $\begin{array}{l}\text { Method of percent- } \\
\text { ages - classical } \\
\text { distributions }\end{array}$ \\
\hline & M4 & & & & & & & & & $\mathrm{x}$ & $\mathrm{x}$ & \\
\hline \multirow{4}{*}{ B1 } & M2-1,1,a2-1 & $\mathrm{x}$ & & $\mathbf{x}$ & & & & $\mathrm{x}$ & & & & \\
\hline & M1-3,6 & & $\mathrm{x}$ & & & $\mathrm{x}$ & & $\mathrm{x}$ & & & & $\begin{array}{l}\text { Matching normal } \\
\text { distribution by } \sigma_{\mathrm{c}} \\
\text { (ANOVA) }\end{array}$ \\
\hline & M1-1,4 & $\mathrm{x}$ & & & $\mathrm{x}$ & & & & & & & $\begin{array}{l}\text { Approximate } \\
\text { method }\end{array}$ \\
\hline & M4 & & & & & & & & & $\mathrm{x}$ & $x$ & \\
\hline \multirow{4}{*}{ B2 } & M1-3,6 & & $\mathbf{x}$ & & & $\mathbf{x}$ & & & & & & $\begin{array}{l}\text { MRN-mixture } \\
\text { of the normal dis- } \\
\text { tributions; method } \\
\text { of percentages }\end{array}$ \\
\hline & M2-1,1,a2-1 & $\mathrm{x}$ & & $\mathbf{x}$ & & & & $\mathrm{x}$ & & & & $\begin{array}{l}\text { Approximate } \\
\text { method }\end{array}$ \\
\hline & M2-1,1,a2-2 & $\mathbf{x}$ & & $x$ & & & & & $x$ & & & Research needed \\
\hline & M4 & & & & & & & & & $\mathrm{x}$ & $\mathrm{x}$ & \\
\hline \multirow[t]{3}{*}{ B3 } & M1-3,6 & & $\mathbf{x}$ & & & $\mathbf{x}$ & & & & & & $\begin{array}{l}\text { MRN-mixture } \\
\text { of the normal dis- } \\
\text { tributions; method } \\
\text { of percentages }\end{array}$ \\
\hline & M2-1,1,a1 & $\mathbf{x}$ & & $\mathbf{x}$ & & & $\mathbf{x}$ & & & & & $\begin{array}{l}\text { Approximate } \\
\text { method }\end{array}$ \\
\hline & M4 & & & & & & & & & $\mathrm{x}$ & $\mathrm{x}$ & \\
\hline \multirow{3}{*}{ B4 } & M2-1,1,a2-1 & $\mathrm{x}$ & & $\mathrm{x}$ & & & & $\mathrm{x}$ & & & & \\
\hline & M1-3,6 & & $\mathbf{x}$ & & & $\mathbf{x}$ & & $x$ & & & & $\begin{array}{l}\text { Matching normal } \\
\text { distribution by } \sigma_{\mathrm{c}} \\
\text { (ANOVA) }\end{array}$ \\
\hline & M4 & & & & & & & & & $\mathrm{x}$ & $\mathrm{x}$ & \\
\hline \multirow[t]{2}{*}{$\mathrm{C} 1$} & M1-3,6 & & $\mathbf{x}$ & & & $\mathbf{x}$ & & & & & & $\begin{array}{l}\text { MRN-mixture } \\
\text { of the normal dis- } \\
\text { tributions; method } \\
\text { of percentages }\end{array}$ \\
\hline & M4 & & & & & & & & & $\mathrm{x}$ & $\mathrm{x}$ & \\
\hline \multirow[t]{2}{*}{$\mathrm{C} 2$} & M1,3,6 & & $\mathbf{x}$ & & & $\mathbf{x}$ & & & & & & $\begin{array}{l}\text { MRN-mixture of } \\
\text { the normal distri- } \\
\text { butions; method } \\
\text { of percentages }\end{array}$ \\
\hline & M4 & & & & & & & & & $\mathrm{x}$ & $\mathrm{x}$ & \\
\hline
\end{tabular}


Table 3. Potential methods for determining the natural capability of the particular types of the processes (cont.)

(source: own study)

\begin{tabular}{|c|c|c|c|c|c|c|c|c|c|c|c|c|}
\hline \multirow{3}{*}{$\begin{array}{c}\text { Own } \\
\text { mo- } \\
\text { del }\end{array}$} & \multirow{3}{*}{ Method } & \multicolumn{2}{|c|}{ I } & \multicolumn{3}{|c|}{ d } & \multicolumn{3}{|c|}{ a } & \multirow{3}{*}{$F(L)$} & \multirow{3}{*}{$\mathbf{F}(\mathbf{U})$} & \multirow{3}{*}{ Comments } \\
\hline & & \multirow[b]{2}{*}{$\bar{\lambda}$} & 3 & 1 & 4 & 6 & 1 & \multirow{2}{*}{\begin{tabular}{|c|}
$\mathbf{2 - 1}$ \\
ANOVA \\
$\sigma_{c}$
\end{tabular}} & \multirow{2}{*}{$\begin{array}{c}\mathbf{2 - 2} \\
\text { ANOVA } \\
\sigma_{k}\end{array}$} & & & \\
\hline & & & $X_{50}$ & $\overline{S^{2}}$ & $\bar{S}$ & $\begin{array}{l}X_{0,135} \\
X_{99,9865}\end{array}$ & $R_{s}$ & & & & & \\
\hline D1 & M1,3,6 & & $\mathbf{x}$ & & & $\mathbf{x}$ & & & & & & \\
\hline & M4 & & & & & & & & & $\mathrm{x}$ & $\mathrm{x}$ & \\
\hline D2 & M1,3,6 & & $\mathbf{x}$ & & & $\mathbf{x}$ & & & & & & $\begin{array}{l}\text { MRN-mixture } \\
\text { of the normal dis- } \\
\text { tributions; method } \\
\text { of percentages }\end{array}$ \\
\hline & M4 & & & & & & & & & $\mathrm{x}$ & $\mathrm{x}$ & $\begin{array}{l}\text { MRN-mixture } \\
\text { of the normal dis- } \\
\text { tributions; method } \\
\text { of percentages }\end{array}$ \\
\hline D3 & M1,3,6 & & $\mathbf{x}$ & & & $\mathbf{x}$ & & & & & & $\begin{array}{l}\text { MRN-mixture } \\
\text { of the normal dis- } \\
\text { tributions; method } \\
\text { of percentages }\end{array}$ \\
\hline & M4 & & & & & & & & & $\mathrm{x}$ & $\mathrm{x}$ & \\
\hline E1 & M1,3,6 & & $\mathbf{x}$ & & & $\mathbf{x}$ & & & & & & $\begin{array}{l}\text { MRN-mixture } \\
\text { of the normal dis- } \\
\text { tributions; method } \\
\text { of percentages }\end{array}$ \\
\hline & M1,3,6 & & $\mathrm{x}$ & & & & & $\mathrm{x}$ & & & & $\begin{array}{l}\text { Normal by } \sigma_{\mathrm{m}}-\text { in } \\
\text { particular cases } \\
\text { after checking the } \\
\text { consistency. } \\
\text { Research needed. }\end{array}$ \\
\hline & M4 & & & & & & & & & $\mathrm{x}$ & $\mathrm{x}$ & \\
\hline E2 & M1,3,6 & & $\mathbf{x}$ & & & $\mathbf{x}$ & & & & & & $\begin{array}{l}\text { MRN-mixture } \\
\text { of the normal dis- } \\
\text { tributions; method } \\
\text { of percentages }\end{array}$ \\
\hline & M4 & & & & & & & & & $\mathrm{x}$ & $\mathrm{x}$ & \\
\hline where: & & & & & & & & & & & & \\
\hline $\begin{array}{l}\bar{X} \text { is t } \\
X_{p} \text { is } \\
\bar{S}^{2} \text { is } \\
\bar{S} \text { is } \mathrm{t} \\
R_{s} \text { is }\end{array}$ & $\begin{array}{l}\text { he mean value } \\
\text { the quantile o } \\
\text { the mean from } \\
\text { he modified } m \\
\text { the range of th }\end{array}$ & n of & $\begin{array}{l}\text { charac } \\
\text { ze } p(p \\
\text { riance } \\
\text { the sta } \\
\text { of the }\end{array}$ & $\begin{array}{l}\text { risti } \\
(1, \\
\text { f the } \\
\text { dard }\end{array}$ & $\begin{array}{l}\text { n-ele } \\
\text { devic }\end{array}$ & $\begin{array}{l}\text { e random } \\
\text { 00) in the } \\
\text { nent samt } \\
\text { tions of th } \\
\text { 3) }\end{array}$ & $\begin{array}{l}\text { sampl } \\
\text { match } \\
\text { les (1 } \\
\text { sam! }\end{array}$ & $\begin{array}{l}\text { le } \\
\text { hed, statistic } \\
\text { ples (n-elen }\end{array}$ & cal distribut & $\begin{array}{l}\text { tion } \\
\text { les) (11 }\end{array}$ & & \\
\hline
\end{tabular}


The lower and upper inconsistency fractions can be estimated from the dependencies

$$
\begin{aligned}
& \hat{\mathrm{p}} \mathrm{U}=1-\Phi\left(\mathrm{z}_{1-\hat{\mathrm{p}} \mathrm{U}}\right)=1-\Phi\left(\frac{\mathrm{USL}-\mu}{\sigma}\right) \\
& \hat{\mathrm{p}} \mathrm{L}=\Phi\left(\mathrm{z}_{\hat{\mathrm{p} L}}\right)=\Phi\left(-\mathrm{z}_{1-\hat{\mathrm{p} L}}\right)=\Phi\left(\frac{\mathrm{LSL}-\mu}{\sigma}\right)
\end{aligned}
$$

where:

$\Phi($ ) - is the cumulative distribution function of the standardized normal distribution.

In case of the normal distribution and known capability indicators calculated by means of the classic methods (formulas 14-18), the range limits of the specification can be estimated based on the standardized normal distribution (ISO/TR 22514-4:2007, p.23)

$$
\begin{aligned}
& \mathrm{z}_{\hat{\mathrm{p}} \mathrm{U}}=3 \hat{\mathrm{C}}_{\mathrm{pu}} \\
& \mathrm{z}_{\hat{\mathrm{p}} \mathrm{L}}=3 \hat{\mathrm{C}}_{\mathrm{pl}}
\end{aligned}
$$

It also results from (36) and (37).

The formulas (35) - (37) can be used for any distributions. In addition, it is assumed that the user has a knowledge about the shape of the distribution describing the process (ISO/TR 22514-4:2007, p.22; ISO 21747:2006, p.28).

In case of the distributions other than normal, the lower and upper inconsistency fractions are estimated from the distribution properly describing the process according to the similar dependencies:

$$
\begin{aligned}
& \hat{\mathrm{p}} \mathrm{U}=1-\mathrm{F}(\mathrm{USL}) \\
& \hat{\mathrm{p}} \mathrm{L}=\mathrm{F}(\mathrm{LSL})
\end{aligned}
$$

where $\mathrm{F}(\mathrm{)}$ is the cumulative distribution function describing the process.

The complementary quantiles of the standard normal distribution corresponding, respectively, the value of the upper and lower limits of the specification of the matched distribution can be calculated from the dependencies

$$
\begin{aligned}
& \mathrm{z}_{1-\hat{p} \mathrm{~L}}=-\mathrm{z}_{\hat{\mathrm{p}} \mathrm{L}}=\Phi^{-1}(\hat{\mathrm{p}} \mathrm{L}) \\
& \mathrm{z}_{1-\hat{\mathrm{p} U}}=\Phi^{-1}(1-\hat{\mathrm{p}} \mathrm{U})
\end{aligned}
$$

where:

$$
\Phi^{-1}()
$$

is the inverted cumulative distribution function of the standardized normal distribution.

If we are dealing with the stationary process, we can determine the capability indicators in the form (35) (37). In the case of the method of inconsistency fraction, only these two indicators can be calculated. There is no possibility of determining the $\hat{\mathrm{C}}_{\mathrm{p}}$ indicator.

In an analogous manner, the performance indicators can be determined. In case of these indicators, the main difference lies on the assumption that the process does not need to be in the state of the statistical control and is not necessarily - as in the case of capability indicators - to be controlled by the control card (ISO/TR 22514-4:2007, p.25). In this case, the calculations of the indicators must be preceded by matching the distribution that well describes the process and the upper and lower fractions of the inconsistency according to equations (44) and (45).

\section{Conclusions}

Synthetically presented statistical models of the processes allow precise real characteristics of theirs. This gives a true picture of the capability and performance of the processes and, by this description, the ability to meet requirements. The model also indicates the statistical causes of the instability and thus directs the operation for process improvement. This is an important theoretical and practical topic. The real, technological-organizational causes must be, however, the subject of detailed analysis and research.

Although the widest application of the proposed models is in production processes and hence is derived from, it doesn't limit their use to this area. With the success, they can be used in a wide range in other processes, which are however repetitive, giving the opportunity to obtain a random sample of sufficient size in terms of estimation of the statistical parameters of the distributions and compliance verification of the empirical distribution with the theoretical distribution. 
A very important issue that is raised in this article is the problem of identifying the process belonging to a particular type of the process. The methods of identification are not presently known in the literature, and this is an important issue that deserves to be solved. A detailed diagram of such a method is presented at Alot and Izdebski (2015).

\section{$7 \quad$ Bibliography}

[1] Alot, Z., Izdebski, W., 2015. Identification of model of the production process for the purposes of quality management. In: Материалы докладов Международной научно-практической конференции “Социально-экономическое развитие организаций ирегионов Беларуси: эффективность иинновации" (ed. Ванкевич Е.В., Шарстнев В.Л., Касаева Т.В., Прокофьева Н.Л., Савицкая Т.Б., Яшева Г.А.). Витебск: УО”ВГТУ”, pp.84-96.

[2] DaimlerChrysler Corporation, Ford Motor Company, General Motors Corporation, 2005. Statistical Process Control Southfield. 2nd Edition. Ml: Automotive Industry Action Group, March 2005.

[3] Dietrych, E., Schulze, A., 2010. Statistical Procedures for Machine and Process Qualification. Six Edition. München: Hanser Fachbuchverlag.

[4] ISO 21747:2006. Statistical method - Process performance and capability statistics for measured quality characteristics. Geneva.

[5] ISO 7870-2:2013. Control charts. Part 2: Shewhart control charts. Geneva.

[6] ISO/TR 22514-4:2007. Statistical method in process management. Capability and performance. Part 4; Process capability estimates and performance measures. Geneva.

[7] Kotz, S., Johnson, N., 1993. Process Capability Indices. London, New York: Chapman \& Hall.
[8] Leksykon Zarzqdzania (Lexicon of Management), 2007. Warszawa: Wydawnictwo Difin.

[9] Montgomery, D.C., 2009. Introduction to Statistical Quality Control. Sixth Edition. New York: John Wiley \& Sons, Inc.

[10] Montgomery, D.C., Runger, G.C., 2003. Applied Statistics and Probability for Engineers. Third Edition. New York: John Wiley \& Sons, Inc.

[11] Oakland, J.S., 2003. Total Quality Management - text with cases. Third edition. Burlington: Butterworth-Heinemann.

[12] Oakland, J.S., 2014. Total Quality Management and Operational Excellence: Text with Cases. Fourth Edition. New York, Abingdon, Oxon: Routledge.

[13] Oakland J.S., 2003. Statistical Process Control. Fifth Edition. Oxford - Burlington: ButterworthHeinemann.

[14] PN-EN ISO 9000, 2006. Systemy zarzqdzania jakościq. Podstawy $i$ terminologia (Quality Management Systems. Fundamentals and Vocabulary). Warszawa: PKN.

[15] PN-ISO 3534-2:2010. Statystyka. Stownik i symbole. Część 2: Statystyka stosowana (Statistics. Glossary and symbols. Part 2.: Applied statistics). Warszawa: PKN.

[16] PN-ISO 8258+AC1:1996. Karty kontrolne Shewharta (Shewhart control charts). Warszawa: PKN.

[17] Taguchi, G., Elsayed, E., Hsiang, T., 1989. Quality Engineering in Production Systems. Singapore: McGraw-Hill Book Co.

[18] Tkaczyk, S., Kowalska-Napora, E., 2012. Strategia Zarzadzania Jakościa (Quality Management Strategy). Warszawa: Wydawnictwo Difin.

[19] Yang, K., El-Haik, B., 2003. Design for Six Sigma. A Roadmap for Product Development. McGraw - Hill. 